\title{
DIGITAL ARCHAEOLOGY, FORENSIC ARCHITECTURE AND INTERACTIVE MODELS AS TOOLS OF RECONSTITUTION OF HISTORICAL MEMORY: The Human Rights Memorial of Minas Gerais Project (Brazil)
}

\author{
Gabriela Pires Machado \\ Pontifícia Universidade Católica de Minas Gerais | Brasil | gabrielapires@pucminas.br \\ Kamila Pacheco Louro Freitas \\ Pontifícia Universidade Católica de Minas Gerais | Brasil | kamila.pacheco@hotmail.com \\ Luísa Antunes de Sousa \\ Pontifícia Universidade Católica de Minas Gerais | Brasil | luisaantunes07@gmail.com \\ Michelle Mayrink Favre \\ Pontifícia Universidade Católica de Minas Gerais | Brasil | mfavre@sga.pucminas.br \\ Pedro Henrique Passos Corrêa \\ Pontifícia Universidade Católica de Minas Gerais | Brasil | pedro-hpc@hotmail.com \\ Thais Gonçalves de Oliveira \\ Pontifícia Universidade Católica de Minas Gerais | Brasil | o.thaisg@gmail.com \\ Victoria Mansur de Calais \\ Pontifícia Universidade Católica de Minas Gerais | Brasil | victoria.calais@gmail.com
}

\begin{abstract}
This paper discusses how history, archaeology, and architecture can work together within restoration and interpretation of older buildings in a multidisciplinary and technologic way especially in territorial contexts of human rights violations. In the last decades, a lot of softwares, tools, and interfaces have emerged with the possibility to connect hypermedia languages, simulating spatial narratives of cultural heritage in virtual reality. This paper addresses these new methodologies of representation of history and memory through projects and case studies of the Human Rights Memorial of Minas Gerais.
\end{abstract}

Keywords: Forensic Architecture; Informational model; Digital archeology; Human rights; Places of Memory

\section{INTRODUÇÃO}

Arquitetura, Arqueologia e História são campos do conhecimento que compartilham 0 interesse pelas conformações e organizações socioespaciais nos mais distintos contextos e temporalidades. Ambas correspondem e atuam no entrecruzamento dos campos disciplinares permitindo a sobreposição de saberes e práticas. Ao longo do século XX e, sobretudo, no pósguerra, tais disciplinas têm sofrido profundas transformações sob um ponto de vista metodológico e também epistemológico, destacando-se o papel central das tecnologias na alteração da produção, circulação e distribuição de conhecimento sobre o passado no mundo contemporâneo.

Em parte, a Arqueologia suscita no grande público a noção de conhecimento dos povos e culturas desaparecidas sob uma visão científica e pautada pelo processo de escavação de determinado território. Também a História e a Arquitetura, especificamente as disciplinas da área de história e teoria, são campos disciplinares que se voltam para o entendimento dos lugares e suas formas de ocupação no tempo e no espaço. No entanto, em uma visão contemporânea nem o passado é dado como algo morto e muito menos a História é um produto acabado. Ambos encontram-se em constante disputa, transformação e dependem do movimento que fazemos, enquanto leitores, no interior de seu campo crítico. Estes três campos compartilham entre si o interesse pelo armazenamento constante de conhecimento em bancos de dados, novos tipos de arquivos, documentos e mídias que na era digital tem demandado novas estratégias de visualização e compartilhamento (Beiguelman, 2014), possuindo, inclusive, a mesma raiz etimológica Arché (Derrida, 2001).

Sob uma perspectiva histórico-filosófica, diversos autores (Foucault, 1987 e 2008; Derrida, 2001; Huyssen, 2014) têm questionado o cientificismo racionalista operante na interpretação dos documentos e testemunhos na escrita da história hegemônica e a relação entre modernidade e 
violência. Ao refletir sobre o sentido das subjetividades na relação entre memória e a problemática dos lugares, Nora (1993) observa que "a história é a reconstrução sempre problemática e incompleta do que não existe mais. A memória é um fenômeno sempre atual, um elo vivido no eterno presente; a história uma representação do passado. Porque é afetiva e mágica, a memória não se acomoda a detalhes que a confortam, ela se alimenta de lembranças vagas, telescópicas, globais ou flutuantes, particulares ou simbólicas, sensível a todas as transferências, cenas, censura ou projeções. [...] A memória se enraíza no concreto, no espaço, no gesto, na imagem e no objeto." (Nora, 1993, p.9). Sem dúvida, as questões que se estabelecem entre história e memória social no contexto de violação dos direitos humanos requerem uma série de cuidados éticos, uma vez que se trata de acontecimentos recentes e cujos atores e espaços dessas disputas narrativas encontram-se entre nós. A pergunta que se faz é: como representar e denunciar a violência espacial com as ferramentas do nosso tempo?

Em relação às tecnologias digitais, Couchot (1993) reflete sobre a passagem da representação à simulação com a chegada da linguagem numérica e dos computadores e observa uma ruptura radical da 'morfogênese da projeção' surgida no Renascimento. Tal crise da lógica figurativa que, segundo o autor, inicia-se e avança com as vanguardas artísticas no início do século $X X$ e os dispositivos de reprodução técnica de imagens também figura em consonância com a crise da história ilustrada abrindo a perspectiva para uma nova história (Burke, 1992). Se a perspectiva dominou as técnicas de representação do mundo moderno, na qual se inclui os sistemas simbólicos da arquitetura (Eisenman, 2008), contribuindo para uma homogeneização das percepções de mundo e uma objetivação das subjetividades em sua 'eficácia e aderência ao real' (Couchot, 1993, p. 41), o sistemas numéricos e a realidade virtual irão abalar essa topologia do sujeito, da imagem e do objeto rumo a uma hibridização.

Trata-se, portanto, de evitar o efeito de espelho que a representação clássica busca em sua captura do 'real bruto' para mover-se por um 'real secundário' em que a lógica da simulação permite trabalhar com camadas de informação que, no caso da arquitetura, são resultantes da dimensão material do edifício ou território e, também, de seus rastros e traços depositados em arquivos fotográficos, cartográficos, jornalísticos e fontes orais que conformam a multiplicidade da própria memória. Nesse contexto híbrido é possível trabalhar com as várias matrizes da linguagem (Santaella, 2005) e o antigo observador se transforma em experimentador, sendo tal experiência resultante da "hibridização entre a imagem e o objeto, a imagem e o sujeito, - a imagem interativa é o resultado da ação do observador sobre a imagem - ele se mantém na interface do real e do virtual, colocando-as mutuamente em contato." (Couchot, 1993, p 47). Ao converter-se em experimentador, torna-se possível manipular o modelo virtual do edifício agindo sobre ele e descobrindo, tal qual o arqueólogo ou o historiador, as condensações e fragmentos de memória que já não se encontram na atualidade daquela arquitetura ou território.

Entender que realidade e virtualidade não configuram opostos permite, na concepção espacial do edifício, conferir novos usos aos espaços concretos sem, contudo, congelar o edifício no tempo já que o processo arqueológico é de natureza destrutiva. A forma interativa do edifício conduz a uma experiência de desterritorialização e constante atualização (Lévy, 1999). Esse movimento de virtualização do espaço ressalta a 'dialética do potencial' uma vez que "um mundo virtual considerando como um conjunto de códigos digitais - é um potencial de imagens, enquanto uma determinada cena, durante uma imersão no mundo virtual, atualiza esse potencial em um contexto particular de uso." (Lévy, 1999, p. 49).

O uso das mídias digitais permite explorar o poder representacional do computador em quatro níveis (Murray, 2012): 1) procedural, entendido como o conjunto de regras executáveis; 2) interativo (participativo), pois convida à ação de manipulação do mundo simulado; 3) enciclopédico, pela quantidade de informação e diferentes formatos de mídia; 4) espacial, uma vez que se abre a distintas formas de navegação (banco de dados ou espaço virtual). O território transforma-se em um dispositivo informacional diagramático, o qual "qualifica a estrutura da mensagem ou o modo de relação dos elementos da informação" (Lévy, 1999) variando os aspectos de interação em função das escolhas e posição do experimentador no interior deste espaço. Tal virtualidade do dispositivo informacional permite desvincular-se do território físico tridimensional e construir um novo território cartografado por proximidade e no qual se dão um complexo híbrido de relações e significações acumuladas e disponibilizadas a serviço da imaginação científica, estética ou lúdica (Luz, 1993).

Uma vez que a memória possui diversas camadas de significação e aderência, tanto em seu sentido individual quanto coletivo, e pensando a partir de uma relação entre memória e tecnologia (Yates, 2007; Pratschke, 2006) buscaremos apontar, nas experiências aqui expostas, como as novos métodos e ferramentas digitais podem colaborar para a simulação espacial sob uma perspectiva da arqueologia da arquitetura (Zarankin, 2003) e da arquitetura Forense (Weizman, 2018). Posteriormente, procuraremos compartilhar as reflexões e estratégias que vêm sendo utilizadas no projeto de extensão universitária para a implementação do Memorial de Direitos Humanos de Minas Gerais em um edifício histórico tombado e reconhecido como centro de tortura e repressão da última ditadura civil-militar brasileira (1964-1985). (antigo Departamento de Ordem Política e Social DOPS/MG). Por meio da utilização de recursos digitais que envolvem modelagem e motor de jogo pretende-se restituir, a partir dos fragmentos dos testemunhos e arquivos, as histórias apagadas, devolvendo-as ao conhecimento do grande público e as gerações futuras em linguagem acessivel e como instrumento de justiça e memória social.

\section{ARQUEOLOGIA DIGITAL}

Entende-se por Arqueologia Digital o ramo disciplinar que trabalha com tecnologias informacionais e mídias digitais aplicadas ao território de investigação como fotografia digital, reconstrução 3D, realidade virtual, sistemas georreferenciados (GIS) e mapeamento por estação total (TST Technology). Um dos objetivos, ainda nos anos 1990, visava o desenho de um processo reconstrutivo para comunicação e interpretação do passado, sobretudo no contexto de redução de danos aos sítios arqueológicos e seu patrimônio cultural (non-invasive techniques). A revolução digital tem interferido significativamente em suas práticas possibilitando métodos analíticos sintonizados com o universo computacional, os quais permitem uma nova forma de abordagem dos dados e da documentação 
permitindo a extroversão da pesquisa arqueológica e uma maior sensibilização do público. Ainda que no campo da arquitetura os projetos digitais e modelos informacionais (BIM) estejam voltados para a simulação e construção de novos edifícios, tem se observado um crescente interesse na área do patrimônio cultural, ainda que sua aplicabilidade esteja, sobretudo, restrita ao restauro do que à compreensão e análise de fenômenos históricos.

Maurizio Forte ressalta que a diferença entre a Virtual Archeology (Forte, 1997) e a Cyber Archeology (Forte, 2007) encontra-se vinculada às próprias fases do desenvolvimento da cibernética, sendo a primeira comprometida com a modelagem gráfica (imagens e vídeos) em continuidade com os esquemas de representação clássicos e seus sistemas de observação, e o segundo um tipo de experiência que passa a potencializar o espaço em tempo real criando um ecossistema digital no qual o usuário interage com a informação. Quanto ao fluxo de trabalho, essas duas abordagens irão se diferenciar pelos seguintes aspectos: na Arqueologia Digital, a captação e processamento dos dados é feita de maneira analógica (analógico-digital) e os modelos virtuais não são arquiteturas interativas. No contexto da Cyber Arqueología, a captação e o processamento passam a ser todo digital, a produção do modelo digital se dá pela captura de dados também de forma digital (scanners 3D, drones, robôs), levando a um modelo virtual interativo e informativo (Forte, 2014).

Surge dessa interação um novo tipo de experiência com o passado que não pode ser reconstruído, mas apenas simulado possibilitando a manipulação de múltiplos passados que podem ser sobrepostos em um mesmo sistema em camadas. Rompe-se com a narrativa única e nos conduz a um passado sempre em potencial, no qual a "subjetividade é coenvolvida na evolução humana gerada pela interação cibernética entre mundos" (Forte, 2014, p. 117). O que nos parece, contudo, promissor é a possibilidade de trocas entre as várias áreas envolvidas e as novas formas de conhecimento e colaboração que podem surgir no âmbito da pesquisa, do ensino e educação de uma maneira mais ampla.

O modelo arqueológico passa a funcionar como um mapa cibernético (Bateson, 1979), no sentido de uma leitura espacial rizomática ou diagramática no qual o território virtual torna-se um meio ou código para interpretar gerando novas realidades e dados a partir desta interação. Independentemente do tipo de realidade que se constrói, sendo mais 'realista' ou não, o essencial da percepção digital é a experiência cultural envolvida da análise e manipulação dos dados (Forte, 2007). A possibilidade de acúmulo em banco de dados das diversas experiências pela qual o território passou em sua transformação - da ocupação original ao próprio inventário de pesquisa também amplia o potencial de cada projeto à medida que se dispõe de mais recursos e tecnologias que possam ser implicadas no projeto (Forte, 2014). Para explicitar as potencialidades desse tipo de abordagem, apresentaremos o projeto Giza 3D da Universidade de Harvard.

\section{O PROJETO GIZA 3D}

O complexo de pirâmides de Giza (Giza Plateau), no Egito, é reconhecidamente um dos mais importantes do mundo e encontra-se em processo de escavação e pesquisa arqueológica desde o princípio do século XIX. Tal fato, somado à degradação e modificação do sítio ao longo do tempo, Ihe confere um grande acúmulo de material de pesquisa como fotografias, mas também objetos retirados de seus lugares de origem. Nesse sentido, um visitante comum possui maior possibilidade de contato com os resquícios dessa cultura em um museu europeu ou norteamericano do que visitando a realidade concreta de Giza ou outro complexo arqueológico do Egito. Ao longo dos anos, acordos internacionais firmados entre países que exploram a região, permitiram preservar os objetos em seus países de origem, o que configura um avanço em termos de direito à memória e história coletiva.

O acúmulo de cerca de 200 anos de escavações levou ao desenvolvimento do Projeto Giza, uma mistura entre arquivos tradicionais (fotos digitalizadas, levantamentos arqueológicos, objetos em metadata) com visualização 3D disponibilizados na internet. O projeto, que envolve uma equipe multidisciplinar de colaboradores e parceiros, foi pensado em duas etapas. A primeira etapa teve início dos anos $2000 \mathrm{com}$ a digitalização integral do acervo - The Giza Archive Project (2000-2011) - hoje localizado no Museum of Fine Arts em Boston (EUA). O acervo consta de 21 mil negativos em placa vítrea, três mil páginas de diários de escavações e metadata de 20 mil achados arqueológicos que foram sobrepostos a uma espécie de malha digital com nós (SQL database) aos quais eram 'linkados' a cada um dos materiais. A partir dessa rede de nós foram criadas ramificações com pontos adicionais com distintos tipos de dados separados por categorias: desenhos das paredes, plantas e cortes da arquitetura, fotografias coloridas, QTVR (Quicktime Virtual Reality) panorâmicas. Embora houvesse um pensamento espacial e uma diagramação da informação, o projeto ainda não contava com uma visualização por simulação dos espaços.

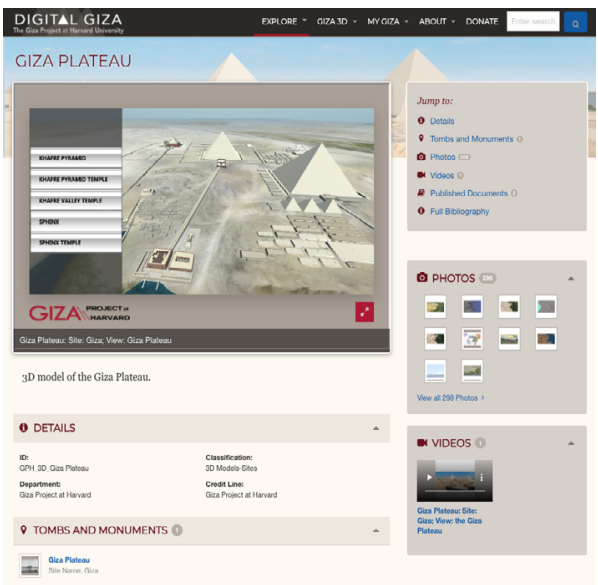

Figura 1. Página do projeto Digital Giza mostrando o menu navegável e opções de interação.

A segunda fase do projeto, iniciada em 2012, concentrouse na zona da Necrópole (Giza Plateau), com o objetivo de criar modelos imersivos visando publicizar o trabalho arqueológico em Giza para um público mais geral cujo conteúdo encontra-se no site do projeto. Somado a isso, o projeto abriu duas oportunidades pedagógicas, a primeira na qual pesquisadores e estudantes encontram-se em curso no Harvard Visualization Center e podem ver e discutir as interpretações, simultaneamente, por meio de uso de tela panorâmica e óculos 3D. A segunda é a possibilidade de cadastrar-se como usuário no site do 
projeto e criar uma biblioteca e arquivo personalizado da sua exploração (My Giza). O site organiza todo o conteúdo coletado na pesquisa e o usuário, ao escolher uma das zonas do projeto, é orientado para uma página onde pode explorar tanto o modelo 3D (Fig. 1, centro da imagem) como a documentação utilizada para a simulação daqueles resultados, sendo organizadas em categorias equivalentes aos arquivos existentes e às novas mídias que são criadas (Fig. 1, a direita da imagem).

A interação com o modelo 3D se dá por meio do motor de jogo Unity, no qual o usuário pode mover-se e visualizar o espaço utilizando as setas do teclado e do mouse. A tela é dividida em três partes: à esquerda encontra-se o menu de navegação; ao centro e ocupando a maior parte da tela, o espaço modelado em 3D; à direita uma planta do espaço onde o movimento do usuário e seu raio de visão são sinalizados, respectivamente, por um ponto vermelho e um cone branco apontando a direção da abertura do olhar (Fig. 2). Embora seja possível navegar pelo modelo, a interação ainda é fraca visto que as informações arquivísticas e bibliográficas continuam fora do modelo interativo.

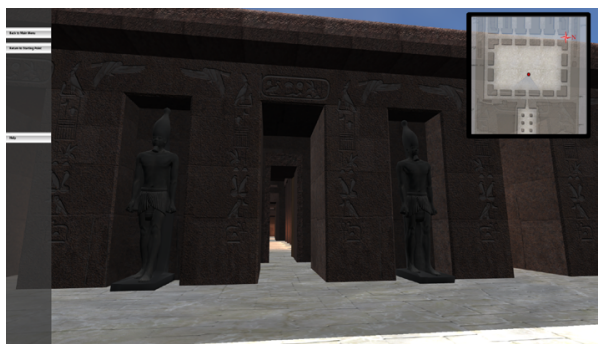

Figura 2. Modelo interativo de navegação. Fonte: Giza Project.

Mais recentemente, ao explorar a Tumba da Rainha Meresankh III, o projeto inovou na interface ao incorporar a plataforma Matterport (Figura 3). Nesse caso, a captura foi feita por câmeras $360^{\circ}$ e transformada em modelo tridimensional utilizando um sistema de inteligência artificial. O formato de interação gerado torna-se muito mais estimulante, visto que o usuário não apenas passeia pelo espaço, mas passa a interagir com o conteúdo acumulado da pesquisa por meio de pontos interativos na própria tela tornando-se verdadeiramente uma leitura em hiperlink. Além disso, permite a captação do espaço em camadas, favorecendo a exploração de modelos complexos como é o caso das câmaras funerárias.

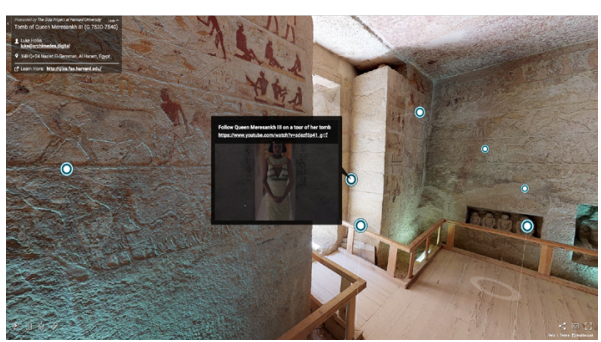

Figura 3. Modelo interativo da Tumba da Rainha Meresankh II gerado no Matterport. Ao centro da imagem, a janela aberta no interior do próprio modelo com link para vídeo no Youtube.

O Digital Giza é, sem dúvida um projeto complexo que só pôde ser pensado e executado em equipe, valendo-se dos recursos tecnológicos que vão sendo atualizados, numa clara demonstração da passagem da Arqueologia Digital para a Cyber Arqueologia. Demonstra também as inúmeras possibilidades de pesquisa e disponibilização de dados para um público não-especialista permitido por esses sistemas inclusive via smartphones, reafirmando a potência transformadora do conhecimento sobre 0 patrimônio cultural e arqueológico do mundo.

\section{ARQUEOLOGIA DA ARQUITETURA E ARQUITETURA FORENSE}

Movendo-se do passado para uma abordagem da realidade da produção do espaço contemporâneo surge a Arqueologia da Arquitetura (AA) cujo objeto de investigação se concentra na dimensão arqueológica da arquitetura, entendendo o edifício tal qual um artefato e, portanto, atravessado por discursos ideológicos e estéticos materializados na forma, função e distribuição dos espaços. Embora seja uma disciplina específica do campo Arqueológico, desenvolve-se sob um olhar multidisciplinar já que busca entender as camadas de significação da cultura material incorporadas pelos diversos atores que utilizaram ou viveram tais espaço. Normalmente, sua aplicação se dá em contextos do Patrimônio Cultural edificado, possuindo metodologias próprias como a análise estratificada e arqueométricas, estudos sociais, de espacialidade e utilização de áreas interna. Destaca-se entre elas, a utilização do modelo Gamma, o qual permite a análise diagramática das hierarquias dos espaços interiores dos edifícios, por meio de um sistema de nós e linhas, podendo ser estendidos à compreensão de espaços disciplinares que marcam a arquitetura da modernidade (Foucault, 1987) ou aqueles vinculados a contextos de violência no contexto póscolonial. Os gráficos gerados permitem o cálculo das medidas de escala, integração e complexidade levando a resultados quantitativos (Blanton, 1994) que permitem a compreensão do objeto de estudo ao longo de vários períodos. A Arqueologia da Arquitetura também incorpora nas suas análises os aspectos subjetivos e a relação do corpo com a espacialidade - psicológicos ou fenomenológicos-, ambos reforçam a relação dialética entre e espaço e sociedade, resultando em narrativas alternativas a confrontar os discursos oficiais (Pellini, Zarankin e Salermo, 2017).

Também no contexto das violências estruturais e políticas aplicadas ao espaço, tem atuado o grupo Forensic Architecture da Goldsmith University of London, cuja coordenação fica a cargo do arquiteto Eyal Weizman desde 2010. Se trata de uma iniciativa colaborativa e multidisciplinar que vincula tecnologias e ferramentas de investigação digitais para apresentar, a pedido de organismos internacionais que atuam na luta por justiça e direitos humanos, evidências materiais e testemunhos sobre conflitos de ordem diversa nos tribunais internacionais. Como descrito no site do grupo, o objetivo é criar uma estética investigativa (Weizman, 2018) que utiliza de linguagens híbridas para se comunicar com um público mais amplo, ou seja, o material produzido tem como objetivo a ampla divulgação e circulação em revistas, meios digitais e museus. No site é possível fazer uma busca por metodologias, categorias ou locais de cada um dos projetos que o grupo tem desenvolvido.

O projeto pretende usar esse tipo de investigação para pensar um campo teórico e histórico ampliado a partir das relações entre arquitetura, mídia e violência conectando o 
material e o testemunho às bases das mídias. O caráter político da iniciativa requer também o uso responsável da tecnologia de forma a não transformar as vítimas e seus testemunhos em meros algoritmos e dados a preencherem uma visualidade específica. Assim, a tecnologia pode ajudar a dar luz a essas narrativas apagadas desde que parta de um trabalho etnográfico aprofundado e cuidadoso. Deve-se evitar 0 achatamento dessas experiências, criando um lugar efetivo para a pluralidade de vozes que seguem, ainda, em disputa no corpo social.

\section{O CASO DA PRISÃO SAYDNAYA (SÍRIA)}

O projeto em questão, publicado em 2016, partiu de uma solicitação da Anistia Internacional para a investigação de casos de tortura e desaparecimentos na prisão Saydnaya ocorridos desde o princípio da crise síria em 2011. Tratase de um edifício projetado nos anos 1970 e localizado a cerca de $25 \mathrm{~km}$ ao norte de Damasco, utilizado para torturar e obter informações de opositores ao governo Assad, este último denunciado nos tribunais internacionais por manter uma rede clandestina de centros de detenção. Para além das questões específicas ligadas a violação de direitos humanos que não configuram objeto de análise desse artigo, iremos nos concentrar aos métodos utilizados e sua extensão ao uso e desenvolvimento de tecnologias digitais analíticas aplicadas ao espaço. As metodologias aplicadas neste projeto envolveram modelagem $3 \mathrm{D}$, testemunho situado, análise de áudio, reconstituição e desenvolvimento de software, assim como uma equipe multidisciplinar composta por arquitetos, psicólogos, técnicos sonoros, programadores e videomakers.

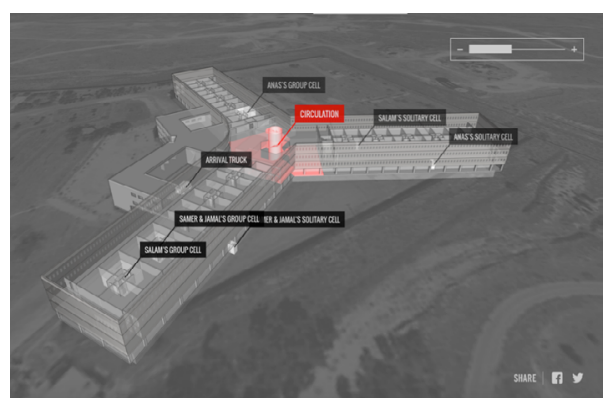

Figura 4. Modelo 3D indicativo da prisão de Saydnaya. Fonte: Forensic Architecture.

Como descreve Eyal Weizman (2018), o projeto foi desenvolvido em duas etapas. A primeira etapa baseou-se na coleta de informações por meio de entrevistas com os sobreviventes, refugiados na Turquia, conduzidas pela Anistia Internacional. Inicialmente a equipe não contava com nenhum registro sobre os espaços internos da prisão e apenas uma fotografia aérea, assim uma primeira modelagem foi feita a partir das informações descritas nas entrevistas (Fig. 4). Uma vez que os sobreviventes eram mantidos vedados e proibidos de se comunicar, movendose de um lado a outro com frequência e sendo mantidos em solitárias completamente escuras, a percepção visual e sonora dos presos era reduzida. Assim, o parâmetro utilizado baseou-se nas diferenças de temperatura, umidade, iluminação, reverberações e ecos dos ambientes para chegar ao desenho da arquitetura do edifício.

Na segunda etapa, as 'memórias narradas' por meio da metodologia de testemunho situado e contando com o suporte de especialistas em psicologia forense, permitiu aos sobreviventes visualizar o modelo criado utilizando realidade virtual. Nesse sentido, a reconstituição baseouse tanto na memória e experiência pessoal de cada testemunho, assim como também o próprio processo de modelagem abriu a possibilidade ativa de resgatar lembranças e detalhes borrados pelo próprio trauma ou violência sofridos. Essa interação ativa dos testemunhos com o modelo 3D, auxiliou a equipe no sentido de corrigir lacunas e contradições que fazem parte do próprio processo de rememoração. Assim, somado a modelagem tradicional, utilizou-se a técnica de modelagem acústica em que softwares, por meio da reprodução de frequências sonoras, permitem simular e confirmar o tamanho de alguns espaços como celas, escadas e corredores (Fig. 5). Acerca do processo, Weizman esclarece que "o modelo surge não como uma síntese redutora, mas como a descrição de ambos os edifícios que nós conhecemos e também das distorções não solucionadas, intervalos e lacunas gravadas nas experiências dos prisioneiros" (Weizman, 2018, p. 91).

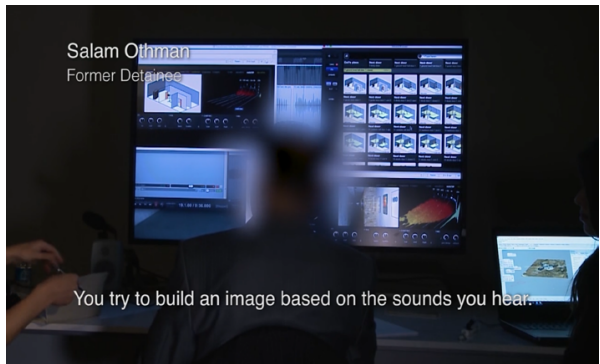

Figura 5. Salam Othman, um dos ex-presos, discutindo o modelo sonoro em conjunto com a equipe. Fonte: Forensic Architecture.

Como dito anteriormente, é objetivo do projeto também a publicização das pesquisas visando criar consciência coletiva sobre conflitos de diversas ordens, assim a linguagem deve ser também acessível. Como não se podia organizar o conteúdo em uma lógica temporal linear, optou-se por trabalhar com "memory objects" (Weisman, 2018, p. 91). Para cada um desses objetos midiáticos foram criados pequenos vídeos que posteriormente foram inseridos em um modelo virtual interativo da prisão (Fig. 6). Assim, o modelo se transformou em um arquivo de testemunhos situados no espaço e no qual o público externo a estes conflitos têm a possibilidade de interagir $\mathrm{e}$ conhecer a versão alternativa ao Estado sobre esse lugar.

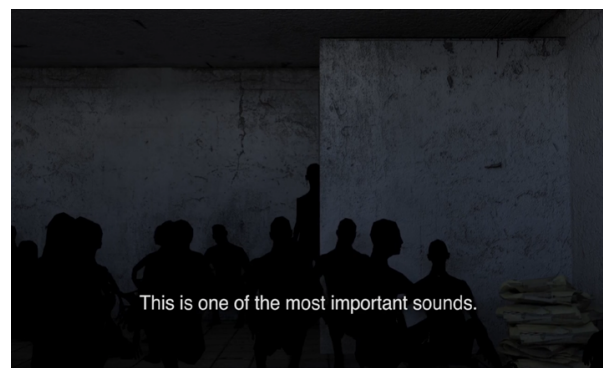

Figura 6. Render de um dos testemunhos situados, posteriormente inserido no modelo virtual. Fonte: Forensic Architecture.

Embora o projeto use recursos tecnológicos de ponta e promova uma reflexão crítica e ética mediada pelo uso de 
tecnologias, o fato de apenas os vídeos serem disponibilizados no site e não o modelo $3 \mathrm{D}$, como no caso do Giza Project, empobrece a experiência. Somado a isso, a não divulgação sobre os programas e softwares utilizados reduz a possibilidade de que outros grupos possam também trabalhar com a perspectiva da Arquitetura Forense em seus territórios.

\section{O PROJETO DO MEMORIAL DE DIREITOS HUMANOS DE MINAS GERAIS (EX-DOPS/MG)}

O projeto do Memorial de Direitos Humanos é um projeto de interesse público, fruto da reivindicação da sociedade civil para reocupar o edifício onde funcionou o Departamento de Ordem Social e Política de Minas Gerais (DOPS/MG) como forma de reparação histórica relativas às violações sofridas neste espaço durante a ditadura civilmilitar brasileira (1964-1985). Trata-se de um projeto de extensão universitária formado por um grupo multidisciplinar de pesquisadores e estudantes das áreas de Arquitetura, História, Museologia, Direito, Antropologia e Jogos Digitais e que juntos se dedicam a investigar e mapear os acontecimentos físicos e simbólicos ocorridos no edifício histórico e reconhecido como centro de tortura e repressão aos mais diversos grupos sociais.

Ainda em desenvolvimento, o trabalho proposto procura, à partir de ampla pesquisa documental, investigação arqueológica e coleta de depoimentos e memórias pessoais, conectar tais documentos a um modelo $3 \mathrm{D}$ do edifício. O fato de o edifício voltar a ter novos usos com a instalação do Memorial, levou toda a equipe a pensar soluções que pudessem dar conta de narrar a história do edifício sem apagá-la. Assim, pelo uso interfaces digitais pretende-se ressituar tais fragmentos de memórias, devolvendo-as ao conhecimento do grande público e às gerações futuras como instrumento de justiça e memória social, considerando tanto o espaço expositivo do futuro memorial, como sua disponibilização pela internet.

\section{O ANTIGO EDIFÍCIO DO DEPARTAMENTO DE ODEM E POLÍTICA SOCIAL (DOPS/MG)}

Trata-se de um edifício modernista tombado pelo patrimônio histórico e localizado em uma das avenidas mais importantes e bairro nobre da cidade de Belo Horizonte (Fig. 7). Foi projetado pelo arquiteto Hélio Ferreira Pinto, cuja atuação no cenário da arquitetura projeta-se em inúmeros edifícios públicos como a Escola Estadual Milton Campos (1954) e o Palácio das Artes (1971), ambos desenvolvidos em colaboração com o Arquiteto Oscar Niemeyer. O edifício foi concebido com o intuito de abrigar o Departamento de Ordem Política e Social (DOPS/MG), como parte da política governamental de Bias Fortes (1956-1961) para a modernização das instituições de segurança pública e reforça o seu uso como instituição carcerária. Inaugurado em 1958, constituiu-se, já naquele momento, como lugar de consolidação do aparato repressivo do Estado, sobretudo a partir do golpe de 1964 e a instalação da Regime Ditatorial Civil-Militar (1964-1985).

A constituição deste espaço como principal centro e símbolo da repressão política e tortura em Minas Gerais, consolidado a partir de 1971 quando soma-se às suas atividades o Destacamento de Operações de Informações coordenado pelo Centro de operações da Defesa Interna do Exército (DOI/CODI), cuja função era implementar as diretrizes de Segurança Interna do governo do General Médici (1969-1974), reconhecido como um dos mais temidos e violentos ditadores. Nesse sentido, a arquitetura do edifício atua como testemunho da política repressiva do Estado articulada por meio da investigação, prisão, interrogatório e assassinato de pessoas ou organizações que se opunham ao regime. Mesmo após a extinção da Polícia Política e redemocratização do país, o espaço continuou sendo utilizado pela polícia civil e houve não apenas a incorporação de sua estrutura física como também de técnicas de violência institucional, inclusive registrando novas denúncias de violação de direitos até o esvaziamento do mesmo em 2015, visando a sua requalificação e transformação em memorial.

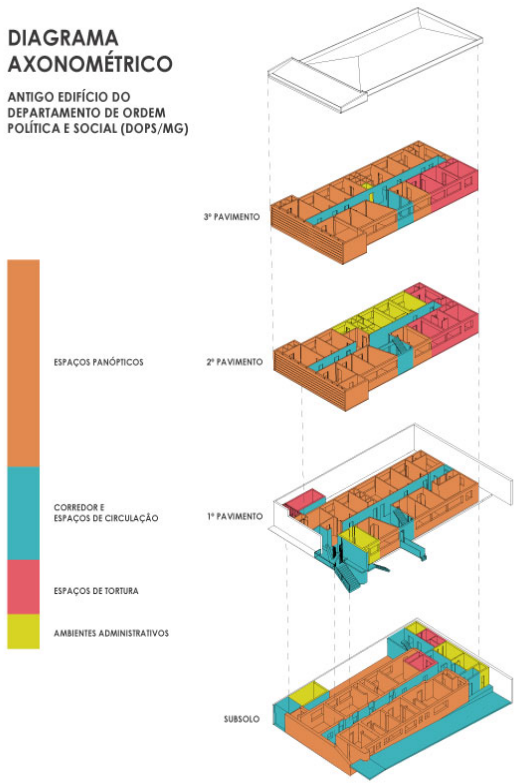

Figura 7. Diagrama 3D do edifício elaborado com base no modelo Gamma. Fonte: Dos autores.

\section{ETAPAS METODOLÓGICAS}

A pesquisa constitui-se de três etapas: 1) Pesquisa histórica de arquivo e levantamento arquitetônico e fotográfico do edifício em seu estado atual; 2) Modelagem digital (SketchUp e Blender) e construção de modelo físico (Corte a laser) visando mapeamento das transformações do edifício no tempo, da pesquisa arqueológica e do testemunho situado das vítimas; 3) Elaboração de modelo informacional que seja capaz de reconstruir a espacialidade do edifício considerando os aspectos formais e também sinestésicos, através de softwares de jogos digitais e dispositivos imersivos (Unreal). O objetivo aqui é dar um panorama geral do desenvolvimento do projeto com relação a reconstituição da espacialidade em modelo 3D.

Por ser um projeto de matriz multidisciplinar e no qual cada uma das áreas trabalha com metodologias específicas, nosso primeiro passo foi criar um modelo gráfico onde 
todos pudessem identificar e inserir informação de seus respectivos bancos de dados. Optou-se por trabalhar com - levantamento do estado mais recente do edifício elaborado para compor o dossiê de tombamento (2015) e contrasta-lo com o projeto original do arquiteto (1958) considerando também as mudanças no âmbito urbano como importante fator de diálogo com a cidade. Embora dispuséssemos de fotos aéreas, plantas e acesso ao prédio vazio, não havia qualquer registro fotográfico dos espaços interiores, seus usos e modificações ocorridas nesse intervalo de tempo.

A equipe da Arqueologia já havia feito um estudo detalhado e aplicado o modelo Gamma para a compreensão do edifício nos dois períodos assinalados, assim, optou-se por seguir a mesma lógica numérica de mapeamento dos cômodos considerando as hierarquias espaciais entre os pavimentos e corredores. Para tal elaboramos um modelo gráfico na ferramenta on-line Mindmeister que permitia a alimentação de dados simultânea pelas diferentes equipes e criou-se um sistema de legendas por cor. Identificou-se por meio dos depoimentos das vítimas diferentes formas de tortura psicológica e física - ocorridas nos espaços do edifício e onde a posição e dimensão dos cômodos para fins de tortura variavam com relação ao contato visual com a rua reforçando o modelo panóptico de sua arquitetura. Dessa forma, o modelo gráfico colaborativo atuou como uma espécie de mecanismo tradutor de informação em trânsito sendo alimentado pelas pesquisas individuais de cada área, principalmente aquelas que não têm domínio de softwares de modelagem 3D. O uso de um digrama gráfico permitiu, a partir de uma ordem numérica, vincular os documentos e registros da pesquisa arqueológica e documental ao modelo gráfico 3D elaborado pela equipe de Arquitetura e Jogos Digitais.

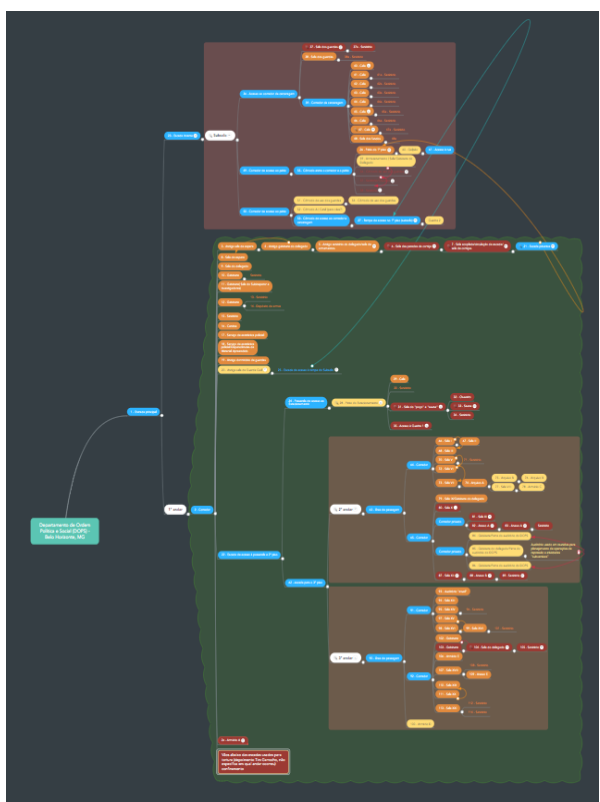

Figura 8. Diagrama colaborativo para mapeamento da informação situada no espaço elaborado pela plataforma on-line Mindmeister. Fonte: Dos autores.
$\mathrm{Na}$ segunda etapa do projeto, foi feita a modelagem integral do edifício (ano 2015) em SketchUp considerando também os passeios, ruas e demais edificações do entorno. A partir dele, geramos também diagramas gráficos em perspectiva axonométrica com a mesma numeração e cores do diagrama gráfico (Mindmeister). Afim de deixar a leitura do ambiente mais didática aos olhos dos futuros visitantes, foi elaborado um diagrama 3D do edifício utilizando uma classificação intuitiva da psicologia das cores - tonalidades frias e quentes de acordo com espacialidade panóptica do antigo DOPS, evidenciando o nível da gravidade dos espaços carcerários (figura 7). Paralelo a isso, migramos o modelo para o software Blender visando a inserção de texturas e luz de forma mais realista.

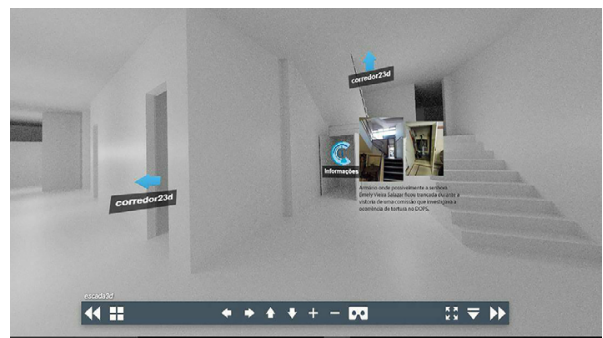

Figura 9. Modelo virtual criado no Unity. Vista do interior do edifício e acesso interativo por pontos a documentos de arquivo originais (em processo). Fonte: Dos autores

A terceira etapa do trabalho, ainda em fase de desenvolvimento', levou a importação do modelo para o motor de jogos Unity. No Unity criou-se um cenário 3d interativo cujo objetivo é, ao final do projeto, desenvolver shads de câmera 360 e possibilidades de percurso tanto nos dispositivos móveis (celulares e tablets) quanto em VR (Projeção de imagens de Realidade virtual 3D). Tal processo tem sido elaborado através de programações e

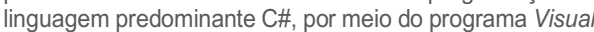
Studio adotando-o como importante ferramenta de edição dos códigos, depuração e a produtividade para criar scripts de editores dentro do Unity para atender as demandas específicas do projeto.

O modelo navegável e interativo tem sido pensado a partir de diferentes tipos de percurso no interior do prédio (presos políticos, torturas e arqueologia da arquitetura) e também os diferentes tipos de documentos e mídias (fotografias, áudio de testemunhos orais, simulações em render, vídeos e documentários, documentos impressos) a serem inseridos em pontos específicos da arquitetura virtual (Figura 9). Ainda que não esteja finalizada, temos observado que, à medida que a pesquisa avança, vão surgindo novos registros e materiais a serem introduzidos ao modelo digital, revelando a demanda por constante atualização da memória histórica na qual softwares e plataformas digitais podem contribuir. Almeja-se que, até a inauguração do Memorial, tenhamos um modelo navegável e interativo que fará parte tanto do projeto expográfico, como também poderá ser acessado via internet por computadores ou dispositivos móveis permitindo, dessa forma, a sua livre circulação e divulgação para a sociedade.

\section{DISCUSSÃO E DESDOBRAMENTOS}

Considerando o histórico de violências observadas na segunda metade do século XX na América Latina, a 
pesquisa amplia o potencial das investigações sobre arquitetura forense a partir do uso de tecnologias de modelagem e mapeamento digital no entrecruzamento entre história, arqueologia e arquitetura por meio de interfaces digitais. No contexto específico do projeto, espera-se que o material produzido, ao utilizar uma linguagem contemporânea e dialogar com as novas gerações que não viveram esse período, cumpra seu caráter didático e possa ser amplamente divulgado nos meios de comunicação e incorporado ao projeto expográfico do Memorial.

Espera-se que outros grupos e organizações sociais, possam também produzir esse tipo de pesquisas e tornálas públicas com o objetivo de potencializar as dimensões da memória histórica evitando que tais atrocidades e violações sigam ocorrendo no futuro.

\section{REFERÊNCIAS}

Azoulay, Ariella (2014). Historia Potencial y otros ensaios. Ciudad de México: CONACULTA.

Beiguelman, G.; Magalhães, A. G. (2014). Futuros Possíveis: Arte, museus e arquivos digitais./ Possible futures: art, museums and digital archives. (1 $1^{\mathrm{a}}$ ed.) São Paulo: Edusp.

Burke, P.(1992). A escrita da história: novas perspectivas. $1^{\text {a }}$ edição. ed. São Paulo: Editora UNESP.

Couchot, E. (1993). Da representação à simulação: evolução das técnicas e das artes da figuração. In A. Parente (org.), Imagem-máquina: A era das tecnologias do virtual ( $4^{\mathrm{a} e d}$ ) (pp. 37-48). São Paulo, SP: Editora 34.

Costa, D. N. B. (2020). Memórias da Repressão, Memórias da Resistência: As marcas da ditadura no DOPS/MG (1964-?) (Dissertação de Mestrado). Belo Horizonte.

Digital Giza: The Giza Project at Harvard University . Retrieved from http://giza.fas.harvard.edu/

Eisenman, Peter (1992). Visões que se desdobram: a arquitetura na era da mídia eletrônica. In K. Nesbitt (Ed.), Uma nova agenda para a arquitetura: antologia teórica (1965-1995). (pp. 600-607). São Paulo, SP: Cosac Naify,

Forte, M. (2014) Virtual reality, cyberarchaeology, teleimmersive archaeology. In Fabio Remondino; Stefano Campana (eds.). 3d Recording and Modelling in Archeology and Cultural Heritage: Theory and best practices (pp. 113-128). Oxford, UK: Archaeopress/ BAR International series.
Forensic Architecture. (2020) Goldsmith University of London. Retrieved from https://forensic-architecture.org/

Foucault, M. (1987) Vigiar e Punir: o nascimento da prisão. Petrópolis: Editora Vozes.

Huyssen, A. (2014) Culturas do passado-presente: modernismos, artes visuais e políticas da memória. ( $1^{\mathrm{a}}$ ed.) Rio de Janeiro: Contraponto.

Hillier, B.; Hanson, J. (1984). The social logic of space. Cambridge: Cambridge University Press.

Lévy, P (1999). Cibercultura. São Paulo. SP: Editora 34.

Luz, R. (1993). Novas imagens: efeitos e modelos. In A. Parente (org.), Imagem-máquina: A era das tecnologias do virtual (4⿳a一ed) (pp. 37-48). São Paulo, SP: Editora 34.

Manuelian, P. D. Giza 3D: Digital Archeology and Scholarly Access to the Giza Pyramids (2013). Digital Heritage, Papers from International Conference, Marseille Oct. 28-Nov. 1, 2013, pp. 1-8.

Murray, J. (2012) Inventing the medium. Londres: Mit Press.

Museum of Fine Arts, Boston. The Giza Archives. Retrieved from http://www.gizapyramids.org/

Pellini, J. R.; Zarankin A.; Salerno, M. A. (2017). Sentidos Indisciplinados: Arqueologia, Sensorialidad y narrativas alternativas. Madrid, ES: JAS Arqueología.

Pratschke, A., Almeida, C. R. P. de, La Rocca, R., \& Januário, F. R. B. (2006). Da ars mnemonica à ars generativa: uma reflexão crítica sobre a produção arquitetônica na era glocal. In Proceedings. Santiago de Chile.

Ricoeur, P. (2007) A memória, a história, o esquecimento. 1a edição. ed. Campinas: Editora UNICAMP.

Tomb of Queen Meresankh III. Giza Project. Retrieved from https://my.matterport.com/show/?m=d42fuVA21To

Weizman, E. (2018) Forensic Architecture. Violence at the threshould of detectability. New York: Zone Books.

Yates, F. (2007). A arte da memória. Campinas, SP: Unicamp.

Zarankin, A. e Senatore, M. X. (2003) Arqueología de la arquitectura, modelando al individuo disciplinado en la sociedad capitalista. Revista de Arqueología Americana, 22: 25-41. 2003

\footnotetext{
' O projeto foi extremamente prejudicado pela pandemia do COVID-19, uma vez que os levantamentos e visitas ao edifício, assim como contato com testemunhas em grande parte do grupo de risco, foram suspensos por tempo indeterminado. Ainda que o projeto se desenvolva sob uma base tecnológica e tenha seguido de forma remota, ficou evidente o quanto a referencialidade e materialidade da arquitetura do edifício são fatores fundamentais para a percepção e desenvolvimento pleno do projeto.
} 